DOI: 10.12731/2658-6649-2020-12-5-32-41

УДК 61.616.9-616-02;616-022.6

\title{
КЛИНИКО-ЛАБОРАТОРНАЯ ХАРАКТЕРИСТИКА СОЧЕТАННЫХ ВИРУСНЫХ КИШЕЧНЫХ ИНФЕКЦИЙ У ДЕТЕЙ В Г.БАКУ
}

\author{
Рустамова Л.И., Кулиева З.М., Гылынджова Ф.В., \\ Исаева М.М., Ахундова Р.М.
}

Цель исследования заключалась в изучении эпидемиологических и клинических особенностей сочетанных вирусных кишечных инфекций среди детей. Этиологическая диагностика острых кишечных инфекияии вирусной этиологии осуществлялась с помощью серологического метода (Meтод иммунохроматографического анализа).

Установлено, что сочетанные вирусныле китечные инфекиии при первичном инфичировании регистрировались в основном у детей первых 2-х лет жизни. В возрастной структуре сочетанных вирусно-вирусных инфекций ротавирусно-аденовирусная ассочиаџия регистрировалась достоверно чаще, чем ротавирусно-астровирусная. Наши исследования показали, что наиболее частой клинической формой при сочетанных вирусных кишечных инфекииях является гастроэнтерит.

Ключевые слова: острые кишечные инфекиии; смешанные вирусные кишечные инфекции; ротавирус; аденовирус; астровирус

\section{THE CLINICO-LABORATORY CHARACTERISTIC OF MIXED VIRAL INTESTINAL INFECTIONS IN CHILDREN IN BAKU CITY}

\author{
Rustamova L.I., Kuliyeva Z.M., Qilindjova F.V., \\ Isayeva M.M., Akhundova R.M.
}

The aim of investigation was to study of epidemiological and clinical characteristics of mixed viral intestinal infections in children. The etiological diajnostic of acute intestinal infection of viral origin have been carried out by serological method (immunochromatographyc method). It was determined that the mixed viral intestinal infections as primary infected mainly have been reg- 
istrated in children of first two years of life. In the age structure of viral-viral intestinal infections the rotaviral-adenoviral association have been oftenly appeared than rotaviral-astroviral association. The our investigations show that in mixed viral intestinal infections the most clinical form is gastroenteritis.

Keywords: acute intestinal infections; mixed viral intestinal infections; rotavirus; adenovirus; astrovirus.

Острые кишечные инфекции (ОКИ) все еще остаются серьезной проблемой педиатрии $[2,6,11]$. По официальным данным Всемирной Организации Здравоохранения ежегодно в мире более 2 млрд. человек переносят эпизод диареи, из них более $60 \%$ заболевших - дети $[9,11]$.

По оценкам Глобального бремени болезней среди 25 главных причин потерянных лет жизни ОКИ занимают 4-ю позицию [10].

С конца XX века наблюдаются значительные изменения в этиологической структуре острых кишечных инфекций. Вирусные кишечные патогены заняли лидирующие позиции среди возбудителей ОКИ [1, 5, 7, 8, 12-14].

В настоящее время возникла необходимость установления значимости ОКИ вирусной этиологии в этиологической структуре ОКИ, связанных с оказанием медицинской помощи (ОКИСМП). Очень часто вопросы диагностики, дифференциальной диагностики и прогнозирования исходов ОКИСМП вирусной этиологии, и особенно сочетанных форм остаются недостаточно исследованными.

В связи с этим, цель наших исследований заключалась в изучении эпидемиологических и клинических особенностей сочетанных вирусных кишечных инфекций среди детей.

\section{Материалы и методы исследования}

Работа выполнена на базе Научно-Исследовательского Института Медицинской Профилактики им. В.Ю. Ахундова в 2019 году. Для решения поставленной цели в работу включены данные 117 пациентов в возрасте 0-3 года с острыми кишечными инфекциями.

Анализ клинико-лабораторных особенностей моно- и сочетанных форм ОКИ проводился на основании установления этиологического агента согласно «Клинических рекомендаций по диагностике и лечению острых кишечных инфекций у детей» (А.В.Горелов, 2006).

Клиническое наблюдение за всеми пациентами осуществлялось с момента поступления больного в стационар и до его выписки. На каждого больного заполнялась специальная учетная карта, в которой были от- 
ражены данные ежедневной фиксации состояния пациентов, динамики клинических симптомов ОКИ, данных клинико-лабораторных и инструментальных обследований, данные эпидемиологического анамнеза. Для изучения эпидемиологических особенностей ОКИ смешанной этиологии у детей использовались описательно-оценочные методы эпидемиологических исследований.

Этиологическая диагностика ОКИ осуществлялась с помощью серологического метода (метод иммунохроматографического анализа, Испания).

Статистическую обработку полученных данных проводили с помощью методов вариационной статистики на компъютере с использованием лицензионных программ Microsoft Excel. Статистический анализ включал в себя анализ количественных и порядковых данных с расчетом значений среднего арифметического (M), стандартного отклонения (SD), ошибки среднего (м), медианы (Me), 95\% доверительного интервала, с оценкой статистической значимости по Фишеру.

\section{Результаты и обсуждение}

В ходе исследования были обследованы 117 пациентов для установления этиологии ОКИ. При обследовании пациентов в динамике в первый день поступления в стационарах до начала этиотропной терапии и на 3-7 сутки пребывания в стационаре были установлены ОКИ СМП у 36 из 117 обследованных, что составило 30,8\%. При этом у 12 больных (33,3\%) была установлена вирусная этиология ОКИСМП. Это подтверждает доминирующую значимость вирусных агентов как в общей этиологической структуре острых кишечных инфекций у детей, так и в структуре острых диарей, связанных с оказанием медицинской помощи.

Среди возбудеителей ОКИ вирусной этиологии у детей всех возрастных групп лидирующие позиции занимала ротавирусы (РВ) $(27,4 \pm 4,1 \%$ в общей структуре и $11,9 \pm 2,2 \%$ в структуре моновирусной ОКИ). В этиологической структуре ОКИ СМП вирусной этиологии значение РВ снижалось $(6,8 \pm 2,3 \%$ в общей структуре и $2,6 \pm 1,8 \%$ в структуре моновирусных ОКИ СМП). Астровирусная (АсВ) и аденовирусная (АдВ) кишечные инфекции как моно вирусная инфекция встречались в $12,8 \pm 3,1 \%$ и $18,8 \pm 3,6 \%$ соответственно (рис. 1).

На современном этапе особо значимую проблему представляют сочетанные вирусные кишечные инфекции. Нами выявлено, что при первичном инфицировании наиболее часто сочетанные формы были зарегистрированы для ротавирусной инфекции - для таких форм составила $11,9 \pm 2,2 \%$. 
Для аденовирусной инфекции характерен $8,6 \pm 1,9 \%$ сочетанных форм. Доля сочетанных форм ротавирусной, аденовирусной и астровирусной инфекций при ОКИ СМП между собой не различалась. Установлено, что при первичном инфицировании ротавирусы выявлялись в основном при моноротавирусной кишечной инфекции, а при ОКИ СМП наблюдались сочетанные формы вирусных кишечных инфекций, в том числе и сочетанные формы ротавирусной инфекции (РВИ).

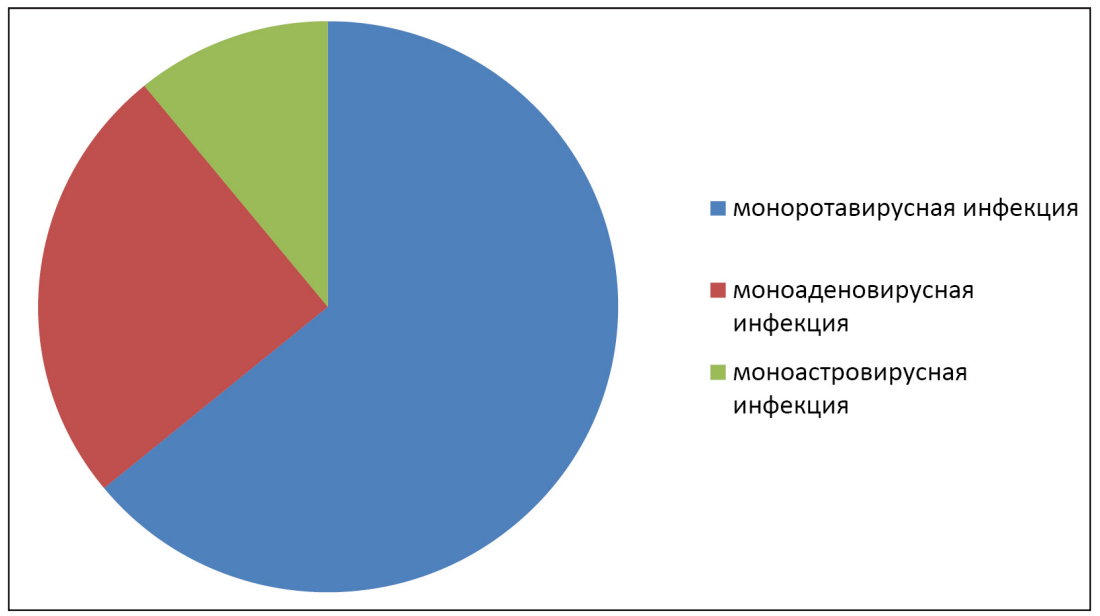

Рис. 1. Этиологическая структура моно вирусных кишечных инфекций у детей

Гендерные характеристики пациентов первичной ОКИ (как для моновирусных кишечных инфекций, так и для сочетанных вирусных кишечных инфекций) и ИСМП дстоверно не различались.

Важным аспектом является возрастные особенности. В ходе исследования установлено, что во всех возрастных группах при первичном инфицировании отмечается доминирование РВИ в возрасте 1-3 года $(33,8 \pm 5,4 \%)$.

При ОКИСМП у детей первого года жизни достоверно чаще регистрируется РВИ, а у пациентов старшего года приобретает значимость аденовирусной инфекции, которая в возрасте 7-12 мес. занимает лидирующие позиции по сравнению с другими вирусными кишечными инфекциями $(33,3 \pm 12,2 \%)(\mathrm{p}<0,05)$ (рис. 2$)$.

Сочетанные вирусные ОКИ при первичном инфицировании регистрировались в основном у детей первых 2-х лет жизни $(35,2) \%$ пациентов. При 
этом в возрастной структуре сочетанных ОКИ вирусно-вирусных инфекций РВИ + АсВИ были диагностированы чаще, чем РВИ+АдВИ $(6,8 \pm 2,3 \%)$ и $5,1 \pm 2,0 \%$ соответственно ( $\mathrm{p}=0,167$ и $\mathrm{p}=0,067, \mathrm{~F}=1,821$ и $\mathrm{F}=2,768)$.

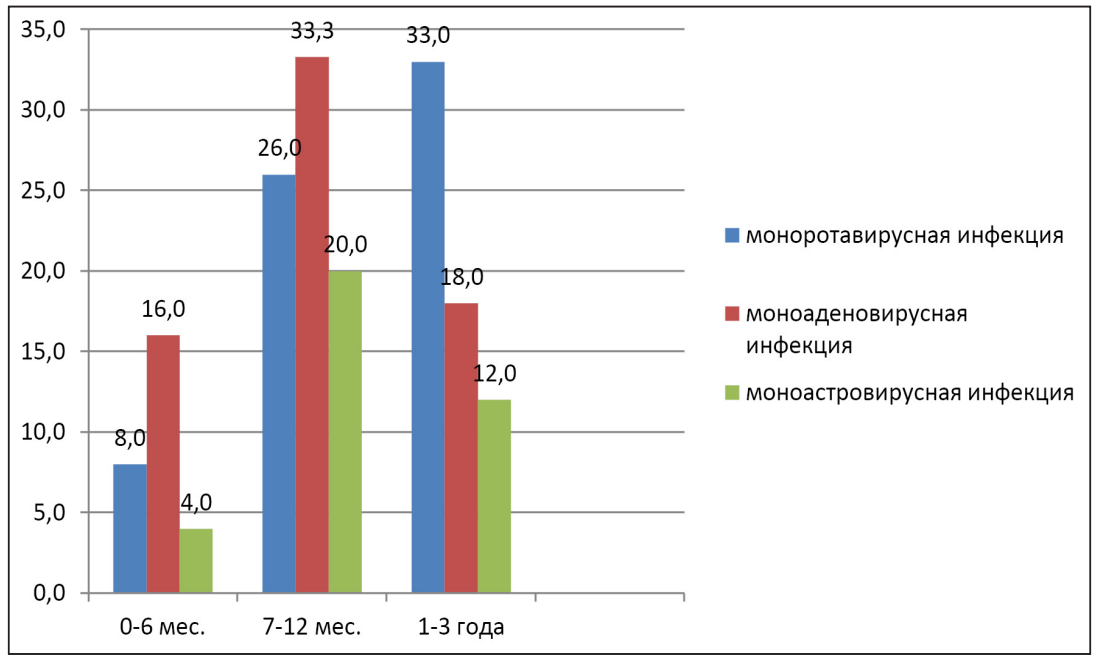

Рис. 2. Этиологическая структура моновирусных кишечных инфекций у детей в возрастном аспекте

В других возрастных группах достоверных различий получено не было.

Максимальная выявляемость сочетанных вирусных кишечных инфекций приходится на возрастную группу 7 мес.-2 лет (32,3\%).

Данный факт требует более пристального внимания к данной категории пациентов.

Наше исследование показало, что наиболее частой клинической формой при вирусных кишечных ОКИ является гастроэнтерит (при РВИ $78,2 \%$, при АдВИ 69,1\%). Однако в ходе исследования у пациентов с подтвержденной моноротавирусной инфекцией в 65,6\% (21 детей) случаев в клинической картине заболевания отмечался острый инфекционный гастроэнтерит. У всех пациентов в этой группе других возбудителей ОКИ (кроме РВИ) выявлено не было.

В литературе также описаны такие клинические формы РВИ, как острый инфекционный энтерит, однако большинство авторов указывают на то, что характерной особенностью данной инфекции является наличие у 50-75\% детей катаральных явлеий $[1,5,6]$. Среди обследованных нами 
детей с ОКИ СМП респираторная форма РВИ отмечалась у 5,3\% пациентов. Анализ клинических проявлений респираторной формы РВИ показал, что субфебрильная лихорадка наблюдалась у 4,7\% детей, ринит умеренного характера выявлялся у $3,9 \%$, гиперемия слизистых оболочек ротоглотки у 4,1\% больных. У 4 больных был установлен сухой кашель $(2,4 \%)$.

Анализ клинической симптоматики этих сочетанных вирусных кишечных инфекций показал, что разграничить клинические проявления сочетанных вирусных кишечных инфекций в зависимости от этиологического фактора трудно. Для того, чтобы отнести какой-либо клиническкий симптом к той или иной сочетанной вирусной кишечной инфекции, следует учитывать клинико-эпидемиологические, возрастные особенности сочетанных вирусных кишечных инфекций и проводить динамическое наблюдение за детьми.

\section{Заключение}

Проведенные нами наблюдения показали,ч то сочетанные вирусные кишечные инфекции разнообразны по своей клинической картине. Большинство клиницистов отмечают, что основными патогенетическими синдромами при сочетанных вирусных кишечных инфекциях являются эксикоз и метаболический ацидоз $[1,5,6,12,14]$.

Многие исследователи указывают диарейный синдром как ведущий синдром при вирусных энтеритах $[3,4,6]$. Как показали наши исследования, частота и характер стула, а также высокая температура, метеоризм, иногда боли в животе также входят в перечень ожидаемых и диагностически значимых симптомов сочетанных вирусных кишечных инфекций. При сочетанных вирусных кишечных инфекциях (РВИ+АдВИ) у детей немаловажное клиническое значение имеет наличие умеренного катарального синдрома. Для конкретизации клинической формы сочетанных вирусных кишечных инфекций необходимо обратить внимание на сезонную выявляемость вирусных кишечных агентов.

Авторы заявляют об отсутствии конфликта интересов.

Исследование не имело спонсорской поддержки.

\section{Список литературы}

1. Безроднова С.М., Гунченко О.В., Алиева Е.В. Клиническая характеристика ротавирусной инфекции в зависимости от возраста // Фундаментальные исследования, 2013, № 9, ч.4. С. 586-590. 
2. ВОЗ. Диарея (Информационный бюллетень), 2017.

3. Горелов А.В., Козина Г.А., Подколзин А.Т. Особенности клиники острых кишечных инфекций аденовирусной этиологии у детей // Инфекционные болезни, 2009, Т. 7, № 1. С. 33-37.

4. Козина Г.А., Горелов А.В., Подколзин А.Т. Клинические особенности острых кишечных инфекций аденовирусной этиологии (F40/41) у детей // Сборник материалов Всероссийской научно-практической конференции «Неотложные состояния при инфекционных заболеваниях у детей: факторы риска, диагностика, терапия», Санкт-Петербург, 2008. С. 56.

5. Мартынова Г.П., Соловьева И.А., Алексеенко А.Н. и др. Клинико-эпидемиологические особенности ротавирусной инфекции у детей первого года жизни // Журнал инфектологии, 2014, 6(2). С. 12-16.

6. Маянский Н.А., Маянский А.Н., Куличенко Т.В. Ротавирусная инфекция: эпидемиология, патология, вакционопрофилактика // Вестник РАМН, 2015, № 1. C. 47-54.

7. Подколзин А.Т., Коновалова Т.А., Яковенко М.Л. и др. Астровирусная инфекция в Российской Федерации // Вопросы вирусологии, 2013, № 3. С. 32-38.

8. Dien-Lan Vu, Boseh A., Pinto R., Guix S. Epidemiology of classic and novel human astrovirus: gastroenteritis and beyond // Viruses, 2017, 9(33), p. 23.

9. Farthing diarrhea in adults and children: a global perspective / World Gastroenterology Organization Global Guidelines, 2017.

10. Global Garden of diseases Health Metrics and Evaluation (IHME), University of Washington, 2013.

11. King C., Glass R., Bresee J., Duggan C. The Management of Acute Diarrhea in Children. MMWR, 2017.

12. Marcelle da Silva, Matias V., Marize M. Rotavirus and astrovirus // Home Global Water pathogen Project, Unesco, 2016, 45 p.

13. Olortegui M., Roubani S., Yori P. et al. Astrovirus infection and diarrhea in 8 countries // Pediatrics, 2018, 14(1), pp. 2017-2032.

14. William M., Marcilio J., Dansen de A. et al. Discovery of novel astrovirus and calicivirus identified in ruddy turnstones in Brazil // Scientific reports, 2019, V. 9, pp. 55-56.

\section{References}

1. Bezrodnova S.M., Gunchenko O.V., Alieva E.V. Klinicheskaya kharakteristika rotavirusnoy infektsii $\mathrm{v}$ zavisimosti ot vozrasta [Clinical characteristics of rotavirus infection depending on age]. Fundamental'nye issledovaniya, 2013, № 9, Part 4, pp. 586-590. 
2. VOZ. Diareya (Informatsionnyy byulleten') [WHO. Diarrhea (Fact Sheet)], 2017.

3. Gorelov A.V., Kozina G.A., Podkolzin A.T. Osobennosti kliniki ostrykh kishechnykh infektsiy adenovirusnoy etiologii u detey [Features of the clinic of acute intestinal infections of adenoviral etiology in children]. Infektsionnye bolezni, 2009, V. 7, № 1, pp. 33-37.

4. Kozina G.A., Gorelov A.V., Podkolzin A.T. Klinicheskie osobennosti ostrykh kishechnykh infektsiy adenovirusnoy etiologii (F40/41) u detey [Clinical features of acute intestinal infections of adenoviral etiology (F40 / 41) in children]. Sbornik materialov Vserossiyskoy nauchno-prakticheskoy konferentsii «Neotlozhnye sostoyaniya pri infektsionnykh zabolevaniyakh u detey: faktory riska, diagnostika, terapiya» [Collection of materials of the All-Russian scientific and practical conference "Emergencies in infectious diseases in children: risk factors, diagnosis, therapy"], St. Petersburg, 2008, p. 56.

5. Martynova G.P., Solov'eva I.A., Alekseenko A.N. et al. Kliniko-epidemiologicheskie osobennosti rotavirusnoy infektsii u detey pervogo goda zhizni [Clinical and epidemiological features of rotavirus infection in children of the first year of life]. Zhurnal infektologii, 2014, 6(2), pp. 12-16.

6. Mayanskiy N.A., Mayanskiy A.N., Kulichenko T.V. Rotavirusnaya infektsiya: epidemiologiya, patologiya, vaktsionoprofilaktika [Rotavirus infection: epidemiology, pathology, vaccine prophylaxis]. Vestnik RAMN, 2015, № 1, pp. 47-54.

7. Podkolzin A.T., Konovalova T.A., Yakovenko M.L. et al. Astrovirusnaya infektsiya v Rossiyskoy Federatsii [Astrovirus infection in the Russian Federation]. Voprosy virusologii, 2013, № 3, pp. 32-38.

8. Dien-Lan Vu, Boseh A., Pinto R., Guix S. Epidemiology of classic and novel human astrovirus: gastroenteritis and beyond. Viruses, 2017, 9(33), p. 23.

9. Farthing diarrhea in adults and children: a global perspective / World Gastroenterology Organization Global Guidelines, 2017.

10. Global Garden of diseases Health Metrics and Evaluation (IHME), University of Washington, 2013.

11. King C., Glass R., Bresee J., Duggan C. The Management of Acute Diarrhea in Children. MMWR, 2017.

12. Marcelle da Silva, Matias V., Marize M. Rotavirus and astrovirus. Home Global Water pathogen Project, Unesco, 2016, 45 p.

13. Olortegui M., Roubani S., Yori P. et al. Astrovirus infection and diarrhea in 8 countries. Pediatrics, 2018, 14(1), pp. 2017-2032.

14. William M., Marcilio J., Dansen de A. et al. Discovery of novel astrovirus and calicivirus identified in ruddy turnstones in Brazil. Scientific reports, 2019, V. 9, pp. 55-56. 


\section{ДАННЫЕ ОБ АВТОРАХ}

Рустамова Лала Ислаховна, кандидат медицинских наук, доцент, заведующая отделом вирусологии

Научно-исследовательский институт медицинской профилактики им. В.Ю. Ахундова

ул. Дж. Джабарлы, 35, г. Баку, АZ1065, Азербайджан

Кудиева Земфира Мехдиевна, доктор медицинских наук, доцент кафедры педиатрии

Азербайджанский государственный институт усовершенствования врачей имени А. Алиева

просп. Тбилиси, 3165, г. Баку, AZ1012, Азербайджан

Гылынджова Фатма Вагифовна, ассистент кафедры Лабораторное дело Азербайджанский государственный институт усовершенствования врачей имени А. Алиева

просп. Тбилиси, 3165, г. Баку, АZ1012, Азербайджан

Исаева Мехрибан Мусаевна, докторант

Университет Одлар Юрду

ул. К. Рагимова, 13, г. Баку, АZ1072, Азербайджан

Ахундова Рена Мамедовна, докторант

Университет Одлар Юрду

ул. К. Рагимова, 13, г. Баку, АZ1072, Азербайджан

iris.ax@mail.ru

\section{DATA ABOUT THE AUTHORS}

Rustamova Lala Islakhovna, Candidate of Medical Sciences, Assistant Professor, Head of Department of Virology

Scientific-Research Institute of Medical Prophylaxis named after V.Y. Akhundov

35, J. Jabbarlı Str., Baku, AZ1065, Azerbaijan

Kuliyeva Zemfira Mekhdiyevna, Doctor of Medical Sciences, Assistant Professor of the Department of Pediatrics Azerbaijan State Advanced Training Institute for Doctors named by A.Aliyev

3165, Tbilisi Ave., Baku, AZ1012, Azerbaijan 
Qilindjova Fatma Vagifovna, Assistant of Department of Laboratory Work Azerbaijan State Advanced Training Institute for Doctors named by A.Aliyev

3165, Tbilisi Ave., Baku, AZ1012, Azerbaijan

Isayeva Mekhriban Musayevna, Doctorant

Odlar Yurdu University

13, Koroghlu Rahimov Str., Baku, AZ1072, Azerbaijan

Akhundova Rena Mamedovna, Doctorant

Odlar Yurdu University

13, Koroghlu Rahimov Str., Baku, AZ1072, Azerbaijan iris.ax@mail.ru 